\title{
PERBANDINGAN PEMANFAATAN LAYANAN KOLEKSI SKRIPSI TERCETAK ATAU HARDCOPY DENGAN LAYANAN KOLEKSI SKRIPSI ONLINE PADA REPOSITORI IAIN KUDUS SEBAGAI SUMBER REFERENSI BAGI MAHASISWA DI UPT PERPUSTAKAAN IAIN KUDUS
}

\author{
Radiya Wira Buwana \\ Institut Agama Islam Negeri (IAIN) Kudus \\ radiyawira2@gmail.com
}

\begin{abstract}
Thesis collection service as a part of reference collection service at IAIN Kudus Library is still the most visited place for visitors who need library collection, especially for final semester students who are preparing their final project or thesis. As a form of excellent service to meet the needs of users of library materials at IAIN KUDUS conducted by the IAIN Kudus Library, the thesis collection service still presents hardcopy or printed editions with limited editions of the last 2 years of the current year to be read on the spot and utilized. With the advancement of technology, the IAIN Kudus library has provided the IAIN Kudus repository / e-prints service to be used by all users at the IAIN Kudus, searching all scientific works, final assignments, theses and online theses that were written by the entire IAIN Kudus academic community. Of the two things above, the author tries to compare of users in the IAIN Kudus library in using online or printed / hardcopy thesis collection services for the fulfillment of the library collections they need.
\end{abstract}

Keywords: Thesis, Repository, Reference Collection 


\begin{abstract}
Abstrak
Layanan koleksi skripsi sebagai salah satu bagian dari layanan koleksi referensi di UPT Perpustakaan IAIN Kudus masih menjadi tempat yang paling sering dikunjungi oleh pemustaka yang membutuhkan koleksi bahan pustaka, terutama bagi mahasiswa semester akhir yang sedang menyusun tugas akhir atau skripsi. Sebagai wujud pelayanan prima untuk memenuhi kebutuhan pemustaka akan sumber bahan pustaka di IAIN Kudus yang dilakukan oleh UPT Perpustakaan IAIN Kudus, layanan koleksi skripsi masih menyajikan hardcopy atau edisi cetak dengan edisi terbatas 2 tahun terakhir dari tahun berjalan untuk bisa dibaca di tempat dan dimanfaatkan. Dengan kemajuan teknologi, UPT perpustakaan IAIN Kudus sudah menyediakan layanan repositori / e-prints IAIN Kudus untuk bisa dimanfaatkan oleh seluruh pemustaka di IAIN Kudus menelusur semua karya ilmiah, tugas akhir, skripsi maupun tesis secara online yang pernah ditulis oleh seluruh civitas akademi IAIN Kudus. Dari dua hal di atas, melalui tulisan ini penulis mencoba membandingkan bagaimana pemustaka di perpustakaan IAIN Kudus dalam menggunakan layanan koleksi skripsi secara online maupun cetak/hardcopy bagi terpenuhinya koleksi pustaka yang mereka butuhkan.
\end{abstract}

Kata Kunci: Skripsi, Repository, Koleksi Referensi

\title{
A. Pendahuluan
}

Skripsi merupakan sebuah karya tulis ilmiah yang wajib disusun oleh mahasiswa sebagai karya monumental yang menentukan keberhasilan dan kelulusan mereka dalam menempuh kegiatan perkuliahan di perguruan tinggi. Sebagai sebuah tulisan ilmiah, skripsi yang tentunya disusun dengan kaidah penulisan tertentu dapat digolongkan sebagai salah satu sumber bahan pustaka yang dilayankan di perpustakaan untuk dimanfaatkan oleh pemustaka di UPT perpustakaan IAIN Kudus, misalnya sebagai sumber referensi jika pemustaka atau mahasiswa ingin mengetahui beberapa tulisan dan penelitian dengan subyek yang hampir sama 
pada masa sebelumnya, serta sebagai acuan untuk mengetahui sistematika penulisan skripsi bagi mahasiswa yang akan memulai menyusun skripsi

UPT Perpustakaan IAIN Kudus, menyediakan layanan koleksi skripsi baik secara online yaitu berupa file soft copy yang tersimpan di repository e-prints IAIN Kudus maupun skripsi dalam bentuk hardcopy atau cetak dan jilid yang disajikan di ruangan layanan referensi UPT perpustakaan IAIN Kudus.

Kemajuan teknologi informasi, mau tidak mau harus bisa merubah paradigma pelayanan perpustakaan untuk menjadi lebih "paperless" oriented daripada "paper" oriented. Dengan pertimbangan lebih praktis, lebih simpel, lebih murah, lebih murah dan lebih efisien, penyajian karya tulis ilmiah, dalam hal ini skripsi di dalam layanan repository software e-prints merupakan sebuah hal yang wajib dilakukan oleh pustakawan dan pengelola UPT perpustakaan IAIN Kudus.

Kemudian, bagaimanakah dengan nasib dari koleksi cetak skripsi di era digital sekarang ini?. Biaya pemeliharaan yang tinggi dan kebutuhan ruangan yang sangat luas menjadi pertimbangan bagi para pengelola perpustakaan untuk melayankan skripsi dalam bentuk cetak kepada pemustaka. Secara umum pemanfaatan koleksi cetak atau hardcopy di era sekarang masih ada, walaupun semakin lama semakin berkurang dengan luasnya dan mudahnya akses internet serta semakin terbukanya atau "open access"nya penerbitan tulisan ilmiah di perguruan tinggi melalui koleksi repository.

Pada prakteknya di UPT Perpustakaan IAIN Kudus belum sepenuhnya civitas akademi di IAIN Kudus yang dapat memanfaatkan koleksi repository tersebut. Kurangnya promosi dan informasi dari perpustakaan sering diklaim oleh pemustaka sebagai hal yang membuat masih masih minimnya penggunaan koleksi skripsi online repository IAIN Kudus. Di sisi lain, masih adanya paradigma kuno dari sebagian mahasiswa yang lebih merasa enjoy dan nyaman untuk menggunakan skripsi hardcopy sebagai sumber 
bahan pustaka, misalnya dengan alasan akses internet yang kurang bagus, ataupun lebih nyaman untuk duduk lama ber-jam-jam di meja perpustakaan untuk menelusur koleksi skripsi perpustakaan,

\section{B. Pembahasan}

\section{Skripsi Sebagai Sebuah Local Content Information}

Skripsi tidak dapat dipisahkan dari dunia pendidikan di perguruan tinggi. Sebagai salah satu bentuk karya tulis ilmiah, skripsi merupakan sebuah tulisan ilmiah yang wajib untuk ditulis oleh mahasiswa sebagai bentuk tugas akhir pada proses perkuliahan mereka di perguruan tinggi. Menurut kamus besar bahasa Indonesia (KBBI), skripsi diartikan sebagai karangan ilmiah yang wajib ditulis oleh mahasiswa sebagai bagian dari persyaratan akhir pendidikan akademisnya ${ }^{1}$. Pada redaksi lain skripsi dapat diartikan sebagai karya ilmiah yang ditulis mahasiswa program S-1 yang membahas topik atau bidang tertentu berdasarkan hasil kajian pustaka yang ditulis oleh para ahli, hasil penelitian lapangan, atau hasil pengembangan (eksperimen) ${ }^{2}$. Menulis skripsi adalah sebuah proses untuk membaca, menulis, meneliti, mengumpulkan data, menyajikan fakta dan berpikir ilmiah secara jelas dan sistematis. Dalam pengerjaan skripsi, mahasiswa dibimbing oleh minimal dua orang dosen pembimbing yang ditunjuk oleh perguruan tinggi yang bersangkutan. Pembimbingan ini dimaksudkan agar hasil skripsi mahasiswa berkualitas baik dari segi isi maupun teknik penyampaianya $^{3}$. Dari proses tersebut diharapkan tersaji sebuah bentuk tulisan ilmiah yang memenuhi ciri-ciri sebagai berikut :

1. Objektif

Keobjektifan ini menampak pada setiap fakta dan data yang diungkapkan berdasarkan kenyataan yang sebenarnya, tidak dimanipulasi. Juga, setiap pernyataan atau simpulan

\footnotetext{
1 "Arti kata skripsi - Kamus Besar Bahasa Indonesia (KBBI) Online," diakses 9 Oktober 2018, https://kbbi.web.id/skripsi. 2013), 4.

${ }^{2}$ Muslich, Masnur, Bagaimana Menulis Skripsi ? (Jakarta: Bumi Aksara, ${ }^{3}$ Muslich, Masnur, 4.
} 
yang disampaikan berdasarkan bukti-bukti yang bisa dipertanggungjawabkan. Dengan demikian, siapa pun dapat mengecek kebenaran dan keabsahan.

\section{Netral}

Kenetralan ini bisa terlihat pada setiap pernyataan atau penilaian, bebas dari kepentingan-kepentingan tertentu baik kepentingan pribadi maupun kelompok. Oleh karena itu, pernyataan-pernyataan yang bersifat mengajak, membujuk, atau memengaruhi pembaca dihindarkan.

3. Sistematis

Uraian yang terdapat pada karya ilmiah dikatakan sistematis apabila mengikuti pola pengembangan tertentu, misalnya pola urutan, klasifikasi, kausalitas, dan sebagainya. Dengan cara demikian, pembaca akan bisa mengikutinya dengan mudah alur uraianya.

4. Logis

Kelogisan ini bisa dilihat dari pola nalar yang digunakanya, pola nalar induktif atau deduktif. Kalau bermaksud menyimpulkan suatu fakta atau data digunakan pola induktif, sebaliknya, kalau bermaksud membuktikan suatu teori atau hipotesis digunakan pola deduktif.

5. Menyajikan fakta (bukan emosi atau perasaan)

Setiap pernyataan, uraian atau simpulan dalam karya ilmiah harus faktual, yaitu menyajikan fakta. Oleh karena itu, pernyataan atau ungkapan yang emosional (menggebu-gebu seperti orang berkampanye, perasaan sedih seperti orang berkabung, perasaan senang seperti orang mendapatkan hadiah, dan perasaan marah seperti orang bertengkar) hendaknya dihindarkan ${ }^{4}$.

Skripsi sebagai sebuah karya ilmiah yang ditulis oleh mahasiswa sebagai civitas akademika sebuah perguruan tinggi

\footnotetext{
${ }^{4}$ Muslich, Masnur, 6-7.
} 
dan disimpan di dalam koleksi perpustakaan dapat digolongkan sebagai sebuah local content information atau informasi muatan lokal. Informasi muatan lokal adalah informasi yang dihasilkan oleh suatu institusi/lembaga penelitian dan atau perguruan tinggi ${ }^{5}$. Informasi muatan lokal sifatnya unik dan hanya dihasilkan dan dimiliki oleh institusi penghasil informasi. Informasi muatan lokal pada perpustakaan perguruan tinggi adalah koleksi karya ilmiah yang meliputi tugas akhir/laporan akhir, skripsi, tesis dan disertasi ${ }^{6}$. Karya ilmiah yang tersimpan di perpustakaan merupakan kekayaan intelektual yang menjadi sumber informasi ilmiah dalam proses pembelajaran dan penelitian. Selain itu keberadaan karya ilmiah yang dihasilkan oleh civitas akademika merupakan cermin untuk menilai kualitas dan visibilitas sebuah perguruan tinggi ${ }^{7}$. Pada perpustakaan perguruan tinggi, koleksi karya ilmiah tersebut disimpan dan dilayankan kepada pemustaka pada ruangan khusus koleksi karya ilmiah dibedakan dengan koleksi pustaka lain di perpustakaan.

Memanfaatkan kemajuan teknologi informasi dan digital, perpustakaan sebagai lembaga deposit yang mempunyai wewenangan untuk menyimpan, mengorganisasikan dan mendistribusikan informasi yang diperoleh untuk kepentingan pemustaka $^{8}$, maka perpustakaan dapat melayankan local content information tersebut sebagai Repository Institusi atau Institutional Repository (IR). Repository Institusi merupakan layanan perpustakaan dalam mengumpulkan, mengelola, menyebarkan dan melestarikan karya ilmiah civitas akademika perguruan tinggi9. Repository Institusi tersebut biasanya disimpan dalam portal atau software tertentu yang bisa di akses terbuka dan lengkap bagi

${ }^{5}$ Fitriani, Rd Erni, "Layanan Digital Content : Layanan Open Access Penelusuran Infromasi Koleksi Karya Ilmiah,” Libraria : Jurnal Ilmu Perpustakaan dan Informasi 5, no. 2 (Desember 2016): 79.

${ }^{6}$ Fitriani, Rd Erni, 79.

7 Ulum, Amirul dan Budiwijaya, M.N, "Pengelolaan Sistem informasi Karya Ilmiah," Pustakaloka 4, no. 1 (2012): 106.

8 Fitriani, Rd Erni, "Layanan Digital Content : Layanan Open Access Penelusuran Infromasi Koleksi Karya Ilmiah," 79.

${ }^{9}$ Fitriani, Rd Erni, 79. 
semua civitas akademika perguruan tinggi yang membutuhkanya. Menurut Arianto dalam Ida, dasar pemikiran yang mendorong pengelolaan dan pengembangan local content yang kemudian dipublikasikan menjadi IR adalah :

1. Untuk meningkatkan reputasi dan peringkat lembaga yang bersangkutan serta mempertahankn kelangsungan simpanan kelembagaan untuk akses jangka panjang (preservasi digital).

2. Agar dapat diakses lebih luas

3. Meningkatkan visibilitas para penulis ${ }^{10}$

\section{Layanan Koleksi Skripsi Cetak di UPT Perpustakaan IAIN Kudus}

Perpustakaan IAIN Kudus sebagai jantungnya perguruan tinggi IAIN Kudus memiliki peran sentral dalam melayani dan menyediakan berbagai sumber informasi dan bahan pustaka yang dibutuhkan oleh pemustaka di IAIN Kudus ( dosen, mahasiswa, tenaga kependidikan, dan masyarakat umum). Salah satu bahan pustaka yang dilayankan di perpustakaan IAIN Kudus adalah karya ilmiah mahasiswa berupa skripsi dan Tesis. Skripsi dan tesis merupakan karya ilmiah yang disusun oleh setiap mahasiswa S1 atau S2 sebagai syarat kelulusan. Koleksi ini tidak dapat dipinjam untuk dibawa pulang, koleksi tersebut hanya untuk dibaca ditempat ${ }^{11}$. Layanan koleksi skripsi di perpustakaan IAIN Kudus dilakukan pada bagian layanan koleksi referensi yaitu di gedung H1 kampus barat IAIN Kudus. Di dalam layanan koleksi referensi, dilayankan skripsi dan tesis dalam bentuk hardcopy atau cetak. Skripsi dalam bentuk hardcopy yang dilayankan di bagian koleksi skripsi berasal dari mahasiswa yang sudah selesai menyelesaikan studinya dengan menghibahkan 1 bentuk cetak hardcopy skripsi

10 Hadna, Ida N, "Peran Perpustakaan dalam Mengembangkan Institutiuonal Repository di UIN Sunan Kalijaga Yogyakarta," Pustakaloka 6, no. 1 (2014): 14 .

${ }_{11}$ Tim Penyusun Buku Panduan UPT Pepustakaan IAIN Kudus Tahun 2018, Buku Panduan UPT Perpustakaan IAIN Kudus Tahun 2018 (Kudus: IAIN Kudus, 2018), 10. 
dan 1 skripsi bentuk softcopy di dalam CD sebagai sebuah syarat mendapatkan surat keterangan bebas pinjaman ${ }^{12}$.

Layanan koleksi skripsi memiliki jam buka dari pukul 8 pagi sampai pukul 12 siang, kemudian setelah jam istirahat dilanjutkan dengan buka dari pukul 13.00 siang sampai pukul 15.30. Sesuai dengan aturan dari buku panduan perpustakaan, koleksi skripsi memang tidak bisa dipinjam oleh pemustaka hanya dibaca ditempat saja saat jam buka pelayanan.

Seiring berjalanya waktu, keberadaan layanan koleksi skripsi banyak mendapat perhatian dan evaluasi dari pihak pengelola perpustakaan IAIN Kudus antara lain sebagai berikut :

1. Tempat kurang representatif

Perbandingan yang tidak seimbang antara luas ruangan koleksi referensi dimana skripsi disajikan, dengan jumlah koleksi skripsi yang ada di perpustakaan IAIN Kudus, serta dengan jumlah pemustaka lain yang memanfaatkan layanan koleksi referensi sering menjadikan ketidaknyamanan bagi pemustaka untuk menggunakan layanan koleksi skripsi.

2. Bentuk Hardcopy Skripsi tidak awet dan perawatanya sulit

Sering sekali, karena faktor usia koleksi banyak skripsi yang rusak lem dan jilidnya sehingga akhirnya banyak koleksi skripsi yang rusak sehingga harus mengalami penyiangan. Selain itu, bentuk fisik skripsi yang besar dan berat sering menyulitkan pengelola perpustakaan di ruangan koleksi referensi untuk men-shelving/ menata jajaran pustaka koleksi skripsi tersebut.

Dari dua hal di atas, maka pihak pengelola perpustakaan IAIN Kudus memutuskan untuk melakukan penyiangan terhadap koleksi skripsi edisi lama dan hanya membatasi untuk menampilkan koleksi skripsi 2 tahun edisi kebelakang pada tahun berjalan. Walaupun hal tersebut pada awalnya sempat mendapat beberapa 2018, 10.

${ }^{12}$ Tim Penyusun Buku Panduan UPT Pepustakaan IAIN Kudus Tahun 
tanggapan negatif dari pemustaka yang memanfaatkan layanan koleksi skripsi, namun berkat penjelasan dari petugas pada ruang layanan referensi tentang adanya skripsi yang bisa diakses pada koleksi repository IAIN kudus, pemustaka bisa menerima bahkan merasa antusias untuk dapat mengakses layanan koleksi repository IAIN Kudus tersebut.

\section{Koleksi Repositori Perpustakaan IAIN Kudus}

Telah disebutkan di atas bahwa sebagai sebuah local content information, koleksi skripsi karya mahasiswa IAIN Kudus dimasukan kedalam koleksi repositori perpustakaan IAIN Kudus. Mengikuti kemajuan teknologi informasi, untuk mengelola koleksi repositori sudah dikembangkan berbagai berbagai aplikasi, baik itu aplikasi yang berbayar maupun aplikasi yang gratis atau open source yang berbasis web kompatibel untuk menyimpan berbagai konten digital.Aplikasi-aplikasi tersebut dikembangkan untuk memenuhi kebutuhan dalam penyimpanan objek digital dan metadata serta untuk mendukung berbagai layanan yang lebih luas dalam sebuah institusi atau lembaga ${ }^{13}$. Perpustakaan perguruan tinggi di Indonesia menggunakan aplikasi yang berbeda untuk mengelola repository, ada eprints, dspace, GDL, SliMs dan sebagian institusi mengembangkan aplikasi sendiri untuk repositorinya ${ }^{14}$. Dalam mengelola local content information yang termasuk juga skripsi, perpustakaan IAIN Kudus memanfaatkan aplikasi e-prints. E-prints adalah perangkat lunak open source yang bisa digunakan untuk menyimpan berbagai makalah, hasil penelitian, gambar, bahkan video ${ }^{15}$. E-Prints adalah perangkat lunak open source yang dikembangkan oleh school of electronics and computer science,

\footnotetext{
Rodliyah, Ummi, "Penggunaan Aplikasi E-Prints Untuk Pengembangan Institutional Repository dan Pengaruhnya Terhadap Peringkat Webometrics Perguruan tinggi di Indonesia," LIBRARIA: Jurnal Perpustakaan 4, no. 1 (Juni 2016): 225.

${ }^{14}$ Rodliyah, Ummi, 225.

15 Dewi, Siti Malaiha dan Rochanah, Rochanah, "Literasi Informasi Mahasiswa STAIN Kudus Dalam Memanfaatkan Digital Library," LIBRARIA: Jurnal Perpustakaan 5, no. 1 (Juni 2017): 188.
} 
University of Southampton, England United Kingdom ${ }^{16}$. Menurut Miftakhul Yazid dalam Ummi Rodliyah, perangkat lunak eprints sudah memenuhi semua indikator-indikator kualitas perangkat lunak kategori karakteristikoperasional perangkat lunak (product operation) dan merupakan software yang mempunyai kualitas cukup baik untuk pengelolaan perpustakaan digital ${ }^{17}$. Penggunaan e-prints dimaksudkan untuk mempermudah pemustaka perpustakaan IAIN Kudus dalam mengakses karya ilmiah dosen ilmiah dosen IAIN Kudus dan karya ilmiah mahasiswa IAIN Kudus (skripsi dan tesis) secara online dengan memanfaatkan akses internet. Untuk mengakses e-prints repository IAIN Kudus, pemustaka dapat melalui website eprints.stainkudus.ac.id.

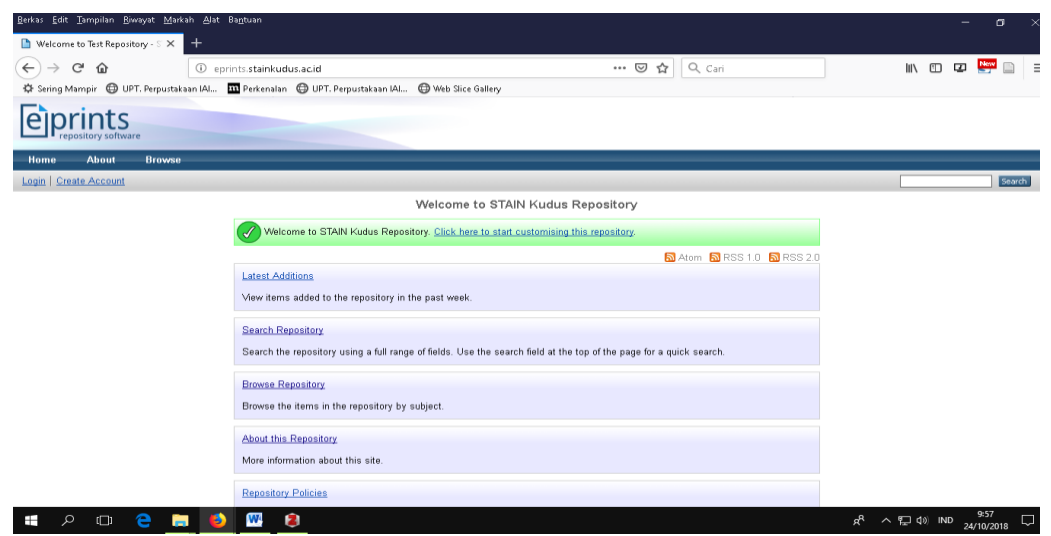

\section{Gambar 1 . Tampilan e-prints repository IAIN Kudus (STAIN Kudus)}

Pengumpulan koleksi skripsi yang akan disimpan dalam koleksi repositori, seperti yang sudah dijelaskan sebelumnya adalah dari mahasiswa IAIN Kudus yang telah menyelesaikan skripsi atau tugas akhirnya, selain mengumpulkan bentuk cetak dari skripsinya juga mengumpulkan skripsi dalam bentuk softcopy file dalam format PDF di dalam CD. Setelah diserahkan, kemudian petugas

${ }_{16}$ Rodliyah, Ummi, "Penggunaan Aplikasi E-Prints Untuk Pengembangan Institutional Repository dan Pengaruhnya Terhadap Peringkat Webometrics Perguruan tinggi di Indonesia," 228.

${ }_{17}$ Rodliyah, Ummi, 229. 
perpustakaan akan melakukan pengecekan dahulu apakah file softcopy dalam CD tersebut sesuai dengan isi skripsi dalam bentuk hardcopy atau belum, jika sudah sesuai maka petugas perpustakaan akan menerima CD tersebut untuk selanjutnya diserahkan kepada bagian unit pengolahan agar file softcopy skripsi dalam CD tersebut bisa diupload langsung ke aplikasi e-prints repositori IAIN Kudus.

Salah satu hambatan yang ditemui dalam proses digitalisasi koleksi skripsi adalah untuk koleksi skripsi dari mahasiswa angkatan lama yang pada waktu lulus hanya menyerahkan skripsi hardcopy saja, sehingga perpustakaan IAIN Kudus tidak memiliki softcopy atau file skripsi tersebut dalam format pdf, sehingga sesuai kebijakan pengelola perpustakaan, maka untuk sementara koleksi skripsi di dalam eprints baru dimulai pada skripsi mahasiswa tahun akademik 2013/2014. Untuk skripsi mahasiswa angkatan sebelumnya, Insya Allah akan segera dimasukan ke dalam koleksi repository IAIN Kudus dengan menunggu adanya piranti pendukung yaitu Rolling Scanner yang bisa menkonversi skripsi hardcopy langsung ke dalam bentuk file PDF pada tahun-tahun yang akan datang.

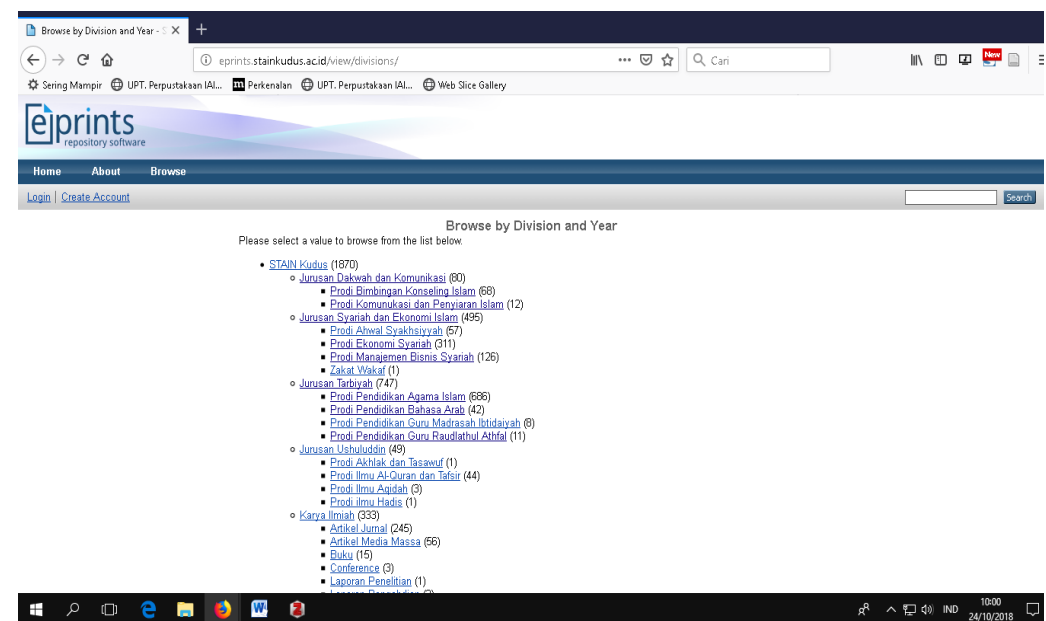

Gambar 2 . Tampilan e-prints repository IAIN Kudus (STAIN Kudus) 
Begitu mudahnya teknologi membantu perpustakaan dalam mengelola koleksi karya ilmiah tergambar jelas dalam aplikasi eprints repositori IAIN Kudus, tidak perlu membutuhkan ruangan yang luas untuk display koleksi skripsi, tidak perlu melakukan penataan koleksi yang rumit, serta perawatan koleksi yang menghabiskan tenaga dan waktu bagi pengelola perpustakaan.

\section{Pemanfaatan Koleksi Skripsi Sebagai Sumber Referensi}

Dalam prakteknya di perpustakaan IAIN Kudus,di satu sisi penulis selalu menemui banyaknya mahasiswa yang sedang mengerjakan skripsi masih secara tradisional menggunakan skripsi versi cetak sebagai sebuah referensi dalam penulisan skripsi mereka. Dengan segala keterbatasan, dalam hal ini edisi cetakan terbatas (hanya 2 tahun cetak) dan tempat yang terbatas pemustaka masih setia untuk mengunjungi tempat koleksi skripsi di ruangan referensi perpustakaan IAIN Kudus untuk mencari bahan referensi. Sedangkan di sisi lain, penulis juga sudah banyak menemui mahasiswa IAIN Kudus yang aktif mengakses koleksi repositori eprints IAIN Kudus, dilihat dari sering banyaknya pemustaka yang menanyakan apa dan bagaimana cara mengakses website eprints IAIN Kudus. Dalam bagian pembahasan ini, penulis akan membandingkan bagaimana perilaku pemustaka dalam memanfaatkan dua layanan koleksi skripsi tersebut sampai bagi terselesaikanya skripsi atau tugas akhir yang sedang mereka kerjakan.

Berdasarkan wawancara penulis dengan beberapa pemustaka di perpustakaan IAIN Kudus, pemustaka yang masih menggunakan layanan koleksi skripsi hardcopy di ruangan referensi perpustakaan IAIN Kudus mengatakan bahwa dengan membaca skripsi hardcopy/cetak tersebut mereka lebih mudah untuk mengetahui detail susunan penulisan skripsi dari awal sampai akhir sehingga bisa menjadi acuan oleh beberapa pemustaka yang sedang menyusun skripsi baik itu acuan metodologi penelitian, sistematika penulisan bahkan bahasan materinya. Seperti yang disampaikan oleh pemustaka saudari Zailatun Nasiha bahwa skripsi tercetak sangat membantu dan bisa mengetahui lebih rinci 
atau detail susunan penulisan skripsi dari awal sampai akhir ${ }^{18}$. Sementara pemustaka Maulina Rohmah mengatakan bahwa dengan menggunakan koleksi skripsi tercetak lebih membantu dalam tata penulisan skripsi ${ }^{19}$. Senada dengan 2 rekanya, Dyah Putri mengiyakan bahwa melalui koleksi skripsi tercetak sangat membantu sekali dalam cara penulisan, format dan isinya ${ }^{20}$. Sri Harningsih pemustaka yang juga mahasiswa IAIN Kudus prodi Ekonomi Syariah masih menggunakan skripsi tercetak jika dalam penulisan skripsi masih dirasa ada yang kurang referensinya ${ }^{21}$. Selain format dan isi, pemustaka Zailatun nasihah masih membaca skripsi tercetak untuk memanfaatkan waktu luang yang dia miliki dengan membaca skripsi di perpustakaan ${ }^{22}$. Sisi negatif dari layanan koleksi skripsi tercetak ini disebutkan oleh Zaenal Arif yang mengeluhkan tata letak dan kerapian rak koleksi skripsi ${ }^{23}$, Sementara Lutfiana lebih mempermasalahkan pada jumlah koleksi skripsi yang semakin sedikit karena banyak yang disiangi oleh pengelola perpustakaan IAIN Kudus ${ }^{24}$.

Dari hasil wawancara di atas dapat penulis sebutkan bahwa hampir sebagian besar pemustaka yang masih memanfaatkan skripsi tercetak/hardcopy merasa lebih mudah untuk mempelajari sistematika penulisan skripsi sebagai acuan dalam menulis skripsi, sebuah hal yang tentunya sangat bisa tercover oleh skripsi online yang tersimpan di dalam aplikasi e-prints repositori IAIN Kudus, tanpa harus berdesak-desak maupun bersempit - sempit di dalam

${ }^{18}$ Hasil wawancara dengan Zailatu Nasihah, Mahasiswa IAIN Kudus Jurusan Tarbiyah prodi PGMI, 30 Oktober 2018.

${ }_{19}$ Hasil Wawancara dengan Maulina Rohmah, Mahasiswa IAIN Kudus Jurusan Syariah Prodi Ekonomi Syariah., 29 Oktober 2018.

20 Hasil Wawancara dengan Dyah Putri , Mahasiswa IAIN Kudus jurusan Syariah Prodi Ekonomi Syariah, 30 Oktober 2018.

${ }_{21}$ Hasil wawancara dengan Sri Harningsih, Mahasiswa IAIN Kudus Jurusan Syariah Prodi Ekonomi Syariah, 29 Oktober 2018.

${ }_{22}$ Hasil wawancara dengan Zailatu Nasihah, Mahasiswa IAIN Kudus Jurusan Tarbiyah prodi PGMI.

23 Hasil Wawancara dengan Zaenal Arif, Mahasiswa IAIN Kudus Jurusan Syariah Prodi MBS., 29 Oktober 2018.

${ }^{24}$ Hasil wawancara dengan Lutfiana, Mahasiswa IAIN Kudus Jurusan Syariah Prodi Ekonomi Syariah, 30 Oktober 2018. 
ruangan koleksi skripsi di ruangan koleksi referensi perpustakaan IAIN Kudus.

Dalam hal pemanfaatan skripsi di e-prints repositori IAIN Kudus, beberapa pemustaka di perpustakaan IAIN Kudus yang ditemui oleh penulis antara lain menyampaikan hal sebagai berikut, Zainal Arif mengungkapkan bahwa sudah sepatutnya setiap kampus memiliki layanan tersebut guna mengikuti perkembangan TI yang semakin maju, dia juga menambahkan bahwa layanan skripsi online sangat membantu bagi teman-temanya yang rumahnya cukup jauh dari kampus, sehingga mereka lebih memilih menggunakan layanan skripsi online tersebut karena dirasa lebih efektif dan efisien $^{25}$. Sementara Ainun Nafis juga mengungkapkan bahwa dia sangat mengapresiasi dengan adanya layanan tersebut karenan layanan ini sangat mempermudah karena bisa diakses kapanpun dan dimanapun ${ }^{26}$. Di sisi lain beberapa mahasiswa memang kurang memanfaatkan layanan eprints repositori dikarenakan kurangnya informasi bahkan ketidaktahuan mengenai layanan tersebut di perpustakaan IAIN Kudus. Seperti Ika Yulianti mahasiswa IAIN Kudus jurusan Syariah prodi Ekonomi Islam yang memang belum pernah sama sekali menggunakan dan mengakses layanan eprints repositori IAIN Kudus. Beberapa mahasiswa bahkan sering merasa kesulitan untuk mengakses skripsi online di eprints repositori IAIN Kudus karena website nya sulit untuk diakses, bahkan karena terkadang susah mengakses maka pemustaka sudah tidak pernah menggunakanya lagi seperti yang disampaikan oleh Lutfiana ${ }^{27}$. Dyah Putri menambahkan bahwa eprints terkadang sulit diakses bahkan terkadang judul yang dicari ada tetapi filenya tidak $\mathrm{ada}^{28}$.

\footnotetext{
${ }^{25}$ Hasil Wawancara dengan Zaenal Arif, Mahasiswa IAIN Kudus Jurusan Syariah Prodi MBS.

${ }_{26}$ Hasil wawancara dengan Ainun Nafis, Mahasiswa IAIN Kudus Jurusan Syariah Prodi ES, 30 Oktober 2018.

${ }_{27}$ Hasil wawancara dengan Lutfiana, Mahasiswa IAIN Kudus Jurusan Syariah Prodi Ekonomi Syariah.

28 Hasil Wawancara dengan Dyah Putri, Mahasiswa IAIN Kudus jurusan Syariah Prodi Ekonomi Syariah.
} 
Dari wawancara dengan beberapa pemustaka di atas, penulis dapat menarik kesimpulan bahwa mereka (para pemustakamahasiswa) sebetulnya sangat menyambut baik penggunaan skripsi online melalui koleksi repositori IAIN Kudus, prinsip teknologi internet yang tidak mengenal batas ruang dan waktu semakin mempermudah mahasiswa yang membutuhkan akses koleksi skripsi lebih cepat, mudah praktis dan efisiensi waktu. Namun, dikarenakan faktor akses ke portal atau website atau aplikasi eprints yang kadang bermasalah sering menghambat kenyamanan pemustaka untuk menikmati layanan skripsi online tersebut, sehingga koleksi skripsi tercetak/hardcopy masih tetap dibutuhkan oleh para pemustaka/user/mahasiswa walaupun untuk menggunakan layanan koleksi tersebut di perpustakaan IAIN Kudus hanya disediakan skripsi yang terbatas dan bertempat pada ruangan yang kurang begitu luas jika dibandingkan dengan jumlah mahasiswa yang menggunakanya.

Beberapa hal yang bisa dilakukan oleh pengelola perpustakaan IAIN Kudus untuk meningkatkan kualitas pelayanan koleksi skripsi tercetak maupun online antara lain sebagai berikut:

1. Melakukan perawatan koleksi skripsi cetak secara berkala dengan melakukan penyiangan koleksi minimal 2 minggu sekali.

2. Berusaha sedemikian rupa untuk melakukan penataan ruangan koleksi skripsi cetak sebaik mungkin, sehingga pemustaka dapat menggunakanya dengan nyaman.

3. Untuk mensiasati ruangan yang tidak cukup besar, pengelola perpustakaan harus cukup jeli untuk bisa memilah kapan harus ada penambahan koleksi skripsi cetak yang sudah di katalogisasi dan mana skripsi versi cetak yang sudah harus disiangi agar jumlahnya selalu seimbang keluar masuknya jumlah koleksi skripsi.

4. Lebih meningkatkan promosi atau pengenalan portal/ web eprints koleksi repositori IAIN Kudus kepada seluruh 
civitas akademika IAIN Kudus, terutama melalui kegiatan pengenalan perpustakaan saat kegiatan OSPEK mahasiswa baru, melalui kegiatan USER EDUCATION, maupun aktif melakukan pengenalan melalui media majalah kampus, bekerjasama dengan himpunan mahasiswa jurusan atau pengenalan melalui website dan akun media sosial perpustakaan IAIN Kudus.

5. Melakukan usulan kepada pimpinan terkait pembelian piranti Rolling Scanner yang berfungsi mengkonversi bentuk skripsi hardcopy ke dalam bentuk digital file PDF untuk menkonversi skripsi-skripsi dari mahasiswa angkatan lama ke dalam bentuk PDF untuk selanjutnya disimpan ke dalam koleksi eprints reposiry IAIN Kudus.

6. Rutin dan aktif menjalin kerjasama dengan bagian teknisi TIPD (teknologi informasi dan pangkalan data) IAIN Kudus agar pengelolaan server dan akses ke website eprints repository IAIN Kudus lancar tanpa gangguan.

\section{Simpulan}

Sebagai sebuah local content information, koleksi skripsi di dalam perpustakaan IAIN Kudus adalah sebuah koleksi yang unik menyimpan tulisan ilmiah hasil karya mahasiswa IAIN Kudus untuk bisa diakses dan dimanfaatkan oleh semua civitas akademika IAIN Kudus.

Memanfaatkan kemajuan teknologi informasi, perpustakaan yang salah satu fungsinya sebagai fungsi deposit, perpustakaan IAIN Kudus menyimpan koleksi skripsi tersebut dalam bentuk repositori IAIN Kudus melalui program open source yang dinamakan eprints untuk bisa diakses secara meyeluruh oleh pemustaka (dosen, tenaga kependidikan, dan mahasiswa) di IAIN Kudus. Di sisi lain, banyak dijumpai pemustaka yang masih menggunakan skripsi bentuk tercetak yang telah dilakukan proses katalogisasi oleh pustakawan dan kemudian disimmpan serta dilayankan di koleksi skripsi ruangan referensi perpustakaan IAIN 
kudus sebagai sumber referensi dan acuan penulisan skripsi di perpustakaan IAIN Kudus.

Dengan koleksi skripsi online yang tidak terbatas ruang dan waktu namun terkadang lemah pada akses internet dan pada beberapa kasus sempat ditemui beberapa kasus eror data, koleksi skripsi online tetap harus diplengkapi dengan adanya koleksi skripsi tercetak yang masih bisa dimanfaatkan pemustaka di perpustakaan IAIN Kudus untuk dibaca di tempat walapupun hanya dalam jumlah dan variasi yang terbatas sehingga terciptalah pelayananan perpustakaan yang lebih "user oriented", pelayanan perpustakaan yang prima, cepat, tepat, dan efisien demi terpenuhinya akses pemustaka akan sumber bahan pustaka yang mereka butuhkan. 


\section{DAFTAR PUSTAKA}

"Arti kata skripsi - Kamus Besar Bahasa Indonesia (KBBI) Online."

Diakses 9 Oktober 2018. https://kbbi.web.id/skripsi.

Dewi, Siti Malaiha, dan Rochanah, Rochanah. "Literasi Informasi Mahasiswa STAIN Kudus Dalam Memanfaatkan Digital Library." LIBRARIA: Jurnal Perpustakaan 5, no. 1 (Juni 2017).

Fitriani, Rd Erni. "Layanan Digital Content: Layanan Open Access Penelusuran Infromasi Koleksi Karya Ilmiah."

Libraria: Jurnal Ilmu Perpustakaan dan Informasi 5, no. 2 (Desember 2016).

Hadna, Ida N. "Peran Perpustakaan dalam Mengembangkan Institutiuonal Repository di UIN Sunan Kalijaga Yogyakarta." Pustakaloka 6, no. 1 (2014).

Muslich, Masnur. Bagaimana Menulis Skripsi ? Jakarta: Bumi Aksara, 2013.

Rodliyah, Ummi. "Penggunaan Aplikasi E-Prints Untuk Pengembangan Institutional Repository dan Pengaruhnya Terhadap Peringkat Webometrics Perguruan tinggi di Indonesia." LIBRARIA: Jurnal Perpustakaan 4, no. 1 (Juni 2016).

Tim Penyusun Buku Panduan UPT Pepustakaan IAIN Kudus Tahun 2018. Buku Panduan UPT Perpustakaan IAIN Kudus Tahun 2018. Kudus: IAIN Kudus, 2018.

Ulum, Amirul, dan Budiwijaya, M.N. "Pengelolaan Sistem informasi Karya Ilmiah.” Pustakaloka 4, no. 1 (2012). 